\title{
Gestão Ambiental Urbana: o caso da Prefeitura Municipal de Ipiranga-PR.
}

\section{Urban Ambient Management: the case of the City hall of Ipiranga - PR}

\author{
Arquimedes da Silva Szezerbicki \\ Centro de Estudo Superior dos Campos Gerais (CESCAGE) e Centro Federal de Educação \\ Tecnológica do Paraná (CEFET) Unidade de Ponta Grossa \\ Professor do CESCAGE e Mestrando no Programa de Pós-Graduação em Engenharia de \\ Produção do CEFET-PR.
}

(42) 9919-1907

Rua Coronel Bittencourt, n. ${ }^{\circ} 484$ - 84010-290 - Ponta Grossa - Paraná

szezerbicki@uol.com.br

\section{Luiz Alberto Pilatti}

Centro Federal de Educação Tecnológica do Paraná (CEFET-PR), Unidade de Ponta Grossa Professor do Programa de Pós-Graduação em Engenharia da Produção do CEFET-PR (42) 3220-4805

Av. Monteiro Lobato, s/n. - Km 4 - 84016-210 - Ponta Grossa - Paraná lapilatti@.pg.cefetpr.br

\section{João Luiz Kovaleski (CEFET -PR)}

Centro Federal de Educação Tecnológica do Paraná (CEFET-PR), Unidade de Ponta Grossa Professor do Programa de Pós-Graduação em Engenharia da Produção do CEFET-PR (42) 3220-4805

Av. Monteiro Lobato, s/n. - Km 4 - 84016-210 - Ponta Grossa - Paraná kovaleski@pg.cefetpr.br

\section{Resumo}

O presente estudo, dentro da área da Gestão Ambiental da Engenharia de Produção, está situado na subárea Políticas Ambientais. O objetivo é discutir como o poder público da cidade de Ipiranga-PR vem executando um projeto de Aterro Controlado e como as condições de 
vida da população urbanas do município são alteradas. Para a consecução do objetivo proposto, além de pesquisa bibliográfica e documental, foram realizadas observações sistemáticas para a composição do corpus documental da pesquisa. O método empregado foi o indutivo. Verificou-se que o município de Ipiranga adotou um modelo de aterro controlado, reduzindo seu custo operacional. As pesquisas realizadas indicaram que a vida útil projetada dos aterros é de 26,5 anos. Houve uma economia considerável na construção do sistema, dispensando a construção de sistemas mais complexos. Conclui-se que a idealização do projeto de construção dos aterros controlados do tipo trincheiras de pequenas dimensões, beneficia tanto a população quanto o meio ambiente, visando à economia do município.

Palavras-chave: Aterro Controlado; Município de Ipiranga - PR; Gestão Ambiental; Políticas Ambientais; Meio Ambiente.

\section{Abstract}


The present study, inside of the area of the Ambient Management of the Engineering of Production, he is situated in the sub-area Ambient Politics. The objective is to argue as the public power of the city of Ipiranga-PR comes executing a project of Fills with earth Controlled and as the conditions of life of the urban population of the city are modified. For the achievement of the objective considered, beyond bibliographical research and documentary, systematic comments for the composition of the documentary corpus of the research had been carried through. The employed method was the inductive one. It was verified that the city of Ipiranga adopted a model of fills with earth controlled, reducing its operational cost. The carried through research had indicated that the projected useful life of the embanking is of 26,5 years. It had a considerable economy in the construction of the system, excusing the construction of more complex systems. The idealization of the project of construction of the controlled embanking of the type trenches of small dimensions is concluded that, in such a way benefits to the population how much the environment, aiming at the economy of the city.

KeyWords: I fill with earth Controlled; City of Ipiranga - PR; Ambient management; Ambient politics; Environment.

\section{Introdução}

Todo país subdesenvolvido aspira a transformar-se em desenvolvido. Para isso, importa toda uma tecnologia e lança-se a um árduo trabalho. Esse esforço determina muitas vezes uma elevação do nível de vida, uma redução da mortalidade, um maior incremento de natalidade e uma crescente demanda de energia. A conseqüência é que os problemas vão se avolumando e a produtividade passa a ser consumida pelo crescimento populacional, aumentando a pobreza e não o nível de vida da população. Além disso, o meio ambiente passa a ser degradado, diaa-dia.

Num país desenvolvido, cada pessoa utiliza direta ou indiretamente cerca de 500 litros diários de água. Tommasi (1997, p. 28) menciona que, "se extrapolarmos o cálculo à população do ano 2025, admitindo que toda ela seja igualmente desenvolvida, o consumo diário de água será então de cerca de sete e meio trilhões de litros." 
Esse cálculo é evidentemente exagerado, mas dá uma idéia do problema que representa o atual crescimento da população humana - e urbana. Entretanto, esse problema fica maior ao se observar que, nos países em desenvolvimento, mais de um terço dos habitantes das grandes cidades não possui rede de abastecimento de água A conseqüência disso é a proliferação de doenças e a degradação ambiental, pela não renovação do meio ambiente.

No Brasil, segundo dados do IBGE, somente um quarto de sua população possui rede de esgotos, cerca de $40 \%$ enterram seus excrementos e seu lixo doméstico em buracos inadequados que não podem ser considerados como fossas, pois destas existem apenas 14,6\%. Cerca de $15 \%$ da população urbana não possui qualquer instalação sanitária (IBGE, 2003). Se o ritmo de urbanização continuar se mantendo, por volta do fim deste século XXI, mais da metade da população da Terra estará vivendo em grandes cidades.

E onde se dá, atualmente, o maior número de problemas decorrentes da urbanização? Exatamente nos países em desenvolvimento.

Justamente naqueles que possuem maiores problemas sanitários, naqueles que não possuem esgotos suficientes para a sua atual população, naqueles que mais problemas possuem com epidemias, com a disposição de seu lixo, com toda uma coleção de poluentes decorrentes de seu progresso industrial. (TOMMASI, 1997, p. 29).

Percebe-se, entretanto, que alguns gestores públicos já se conscientizaram da necessidade de se tomar medidas saneadoras compatíveis à realidade de sua região. Um exemplo disso é o que vem acontecendo em Ipiranga, cidade do interior do estado do Paraná, onde um Projeto de Aterro Controlado está sendo posto em prática, e com bastante sucesso, pois se mostra bastante viável economicamente, bem como visa resolver o problema ambiental do acúmulo de lixo e da coleta de esgotos.

A pesquisa objetiva discutir como o poder público da cidade de Ipiranga - PR vem executando este projeto e como as condições de vida da população urbanas do município são alteradas. Para a consecução do objetivo proposto, além de pesquisa bibliográfica e documental, foram realizadas observações sistemáticas que serviram para ampliar o corpus documental da pesquisa, permitindo discutir como o problema ambiental pode ser resolvido sem grande ônus para a municipalidade.

\section{Ocupação Urbana versus Meio Ambiente}


Segundo Silvio Castro (1999, pp. 39-63), o símbolo da modernização brasileira, pelos idos de 1920, era a crescente industrialização e urbanização. O símbolo da cidade de São Paulo era a fumaça que saía das chaminés das indústrias Matarazzo. A preocupação, advinda da Revolução Industrial, era urbanizar, fabricar, modernizar. O "rural" era visto como algo ultrapassado, símbolo de um país colonial - que o Brasil já havia deixado de ser. O meio ambiente, então, era degradado sem escrúpulos, sem a menor preocupação.

Por isso, concorda-se com o que foi dito no SIMPÓSIO DO INSTITUTO SMITHSONIANO (1968, p. 223):

muitos dos problemas humanos parecem transcender as ciências naturais, determinados que são por fatores históricos e sociais tão complexos. No entanto, é também verdade que a abordagem de todos os problemas precisa levar em consideração as necessidades e as limitações urbanas.

E como o meio ambiente pode ser definido como "o conjunto de elementos e fatores indispensáveis à vida" (BRANCO; ROCHA, 1987, p. 51), o homem passou a perceber que a industrialização e a modernização deveriam acontecer, mas acompanhadas do respeito ao meio ambiente. Assim sendo, passou-se a proteger o ambiente através de multas e sanções (décadas de 1960 e 1970).

Esta evolução levou algumas cidades a integrar o controle ambiental em sua gestão administrativa. "Atender ao presente e gerar respostas setoriais e estanques passou a não ser suficiente; olhar o futuro, horizontalizar a análise e planejar corporativamente passou a ser o caminho natural" (DONAIRE, 1999, p. 37).

Hoje, então, a questão ambiental é um dos assuntos que mais tem atraído a atenção da população, pela valorização que se dá à qualidade de vida e pela percepção de que as conseqüências do descaso com o meio ambiente têm conduzido a situações críticas para a própria sobrevivência da humanidade a longo prazo.

É o que infere Moura (2002, p. 17), ao professar que:

A partir da revolução industrial, ou seja, muito pouco tempo atrás em termos históricos, comparando-se com a presença da vida humana na Terra, que o nível de poluentes jogados na atmosfera, nas águas e no solo, tem crescido exponencialmente, atingindo limites que não permitem mais a aceitação dos antigos procedimentos de diluir e dispersar. 
Destaca-se, neste sentido, que o esgotamento de recursos naturais, incluindo-se a própria água, tem proporcionado sérias preocupações, sobretudo por se verificar que o aumento populacional continua expressivo e sem controle, prevendo-se a falta desses recursos para as futuras gerações.

Seguindo essa realidade, "é preciso entender que nós não herdamos a terra de nossos pais, mas as tomamos emprestadas de nossos filhos" (PROVÉRBIO AMISH in DONAIRE, 1999). Pensar no futuro. Isso é o que o poder público terá de fazer.

\section{O caso da Prefeitura Municipal de Ipiranga - PR}

Ipiranga é uma cidade do interior do Paraná, de pequeno porte, apresentando, no ano de 2003, 14.202 habitantes, sendo 4.504 residentes na área rural e 9.698 constituintes da população urbana.

Apesar de ser uma população relativamente pequena, no ano de 2000 o problema do lixo no município era crítico, mesmo sendo a coleta realizada diariamente. Isso porque, a disposição final do lixo coletado estava sendo efetuada a céu aberto, sem a menor preocupação ambiental em drenar as águas superficiais e controlar a produção de chorume. Outro ponto agravante era o fato de não existir qualquer isolamento da área, permitindo o acesso de famílias carentes, que sobreviviam da coleta de lixo, convivendo em meio aos detritos orgânicos, com moscas, baratas, ratos e outros, estando sujeitas a sérios riscos à saúde.

Após sondagens na área indicada para a implantação do projeto, onde se observou o tipo do solo - que se mostrou argiloso - e a sua quantidade de água, optou-se pelo aterro controlado do tipo trincheiras de pequenas dimensões.

De acordo com Tommasi (1997, p. 31),

O aterro sanitário do tipo trincheiras de pequenas dimensões, "são valas que, escavadas com dimensões apropriadas para o terreno, tipo de solo e quantidade de água do solo, recebem o lixo. (...) a sua cobertura pode ser realizada manualmente."

Pôde-se perceber, então, mais uma vantagem pela escolha do aterro tipo trincheiras: o número e tamanho das valas projetadas permitem estimar a vida útil do aterro. O cálculo é feito pela 
razão entre a área total utilizada do terreno e o tamanho de cada vala, fornecendo o tempo de vida do aterro sanitário (TOMMASI, 1997).

Considerando-se a população apurada no censo populacional realizado pelo Instituto Brasileiro de Geografia e Estatística (IBGE) entre os anos de 2000 (13.552 habitantes, sendo 4.245 na área urbana e 9.307 na área rural) e 2003 (14.202 habitantes, sendo da área urbana 4.504 e da rural 9.698), mostrando uma projeção de 2,70\% a.a., pode-se saber que a área destinada permite uma vida útil acima de 26,5 anos.

As trincheiras foram implantadas, na cidade de Ipiranga - PR, em seqüência, uma após a outra. Inicialmente a primeira e após o preenchimento desta, com vida útil prevista para um mês, implantando-se a segunda trincheira e assim sucessivamente.

Sobre a forma do depósito do lixo nas valas, Tommasi (1997, p. 40) deixa claro que "durante a cobertura das valas o acúmulo de terra deve-se dar apenas em um dos lados".

Segundo dados da Prefeitura Municipal de Ipiranga - PR, os resíduos são descarregados pelo lado livre das valas, sem o ingresso dos veículos no seu interior, iniciando-se pela extremidade na qual a cota de fundo é mais alta. Na seqüência, os resíduos são descarregados por trecho nas valas em compartimentos verticais até que estejam completamente preenchidos. À medida que são depositados, os resíduos são nivelados e cobertos manualmente, utilizando-se a terra acumulada ao lado da vala. O nivelamento e cobertura dos resíduos são realizados diariamente, tolerando-se freqüências menores apenas em circunstâncias especiais. Assim que o primeiro trecho da vala estiver totalmente preenchido, passa-se para outro, repetindo-se as mesmas operações. O nivelamento final da vala fica numa cota superior ao do terreno, prevendo-se prováveis recalques.

Outro ponto importante a ser citado, é que para o projeto estudado foi adotado o Método de Balanço Hídrico para determinação do Volume de líquidos percolados. Segundo Ehrlich (1994, p. 68), este método,

Procura expressar o fluxo da água num aterro, considerando a quantidade de água precipitada sobre o aterro; a fração que escoa superficialmente, em função do tipo de cobertura e da declividade; a parte devolvida à atmosfera pela evapotranspiração; a quantidade de água que se infiltra; a quantidade de água que fica retida na camada de cobertura, em função da espessura e do tipo de solo utilizado; a quantidade de água que atinge os resíduos, podendo gerar líquidos percolados. 
Os cálculos são realizados mês a mês, a partir de valores médios mensais, para o maior número possível de anos de observação. Como resultado, apresentou-se um nível bastante baixo de percolação, o que é favorável para o meio ambiente.

Mesmo assim, em virtude da existência da percolação de líquidos, foi implantado um sistema de coleta e recirculação de chorume, com a finalidade de preservar o lençol freático de qualquer tipo de contaminação. O sistema projetado é constituído de drenos de brita, dispostos no fundo da vala, rede de tubos em PVC, que leva o chorume drenado até um poço de captação, para seu armazenamento provisório.

Para dar destino ao chorume armazenado, optou-se pela sua recirculação dentro das valas extintas, onde foram implantadas tubulações de PVC perfuradas manualmente, que distribuem homogeneamente o chorume, pela superfície do lixo aterrado no interior da vala.

Este sistema permite que os líquidos percolados coletados sejam reinjetados na massa de resíduos, como uma forma de reposição da umidade perdida devido à evapotranspiração.

Além disso, face às dimensões das valas projetadas, com capacidade de acondicionar pequenas quantidades de resíduos, conseqüentemente, há a produção insignificante de gases, resultado da decomposição de materiais orgânicos depositados. A pequena profundidade das valas, também, é um ponto positivo, pois possibilita que os gases eventualmente formados saiam livremente para a atmosfera, sem a possibilidade da formação de acúmulos perigosos, dispensando, portanto, a construção de sistemas especiais de drenagem.

Partindo de dados da própria Prefeitura Municipal de Ipiranga - PR, verificou-se que, em relação aos demais municípios do país, os habitantes da cidade são privilegiados. Isto porque a gestão pública tem como prioridade o bem-estar dos munícipes e a preservação do meio ambiente. Percebe-se isso quando são observados itens como a instalação de rede de água onde $99,61 \%$ da população é beneficiada; coleta de esgoto, com $60,52 \%$ da população atendida, no ano de 2003.

Quanto à extensão de redes, percebe-se, pelo gráfico abaixo, que, entre os anos de 2000 e 2003 houve um aumento de $73 \%$ e o atendimento com esgoto apresentou um crescimento de $108 \%$, sendo que a população obteve um pequeno crescimento. Segundo dados do IBGE, a população, que era de 13.552 habitantes no ano 2000, aumentou para $14.202 \mathrm{em} 2003$.

Gráfico 1 - Crescimento na Extensão e Redes do Município de Ipiranga - PR .

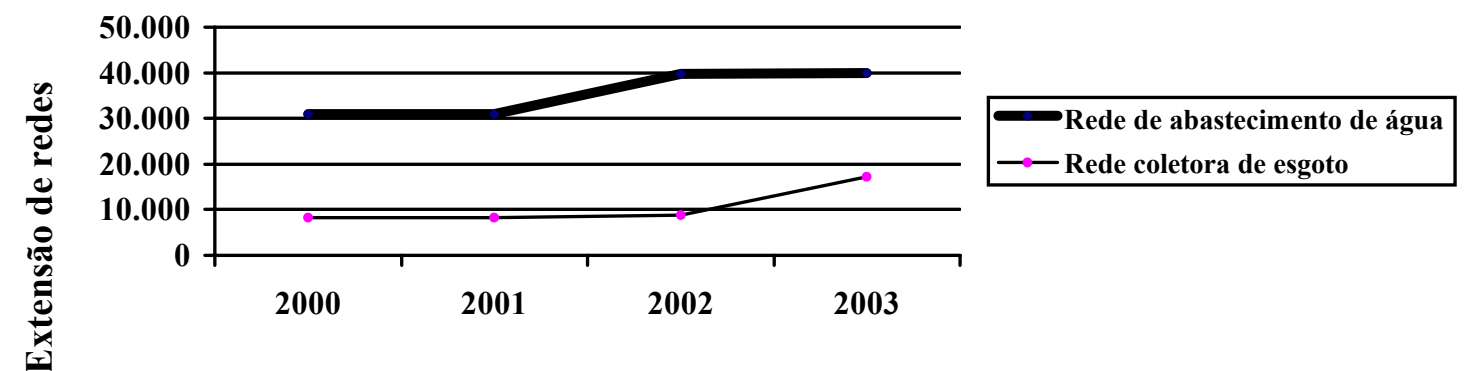


Fonte: Prefeitura Municipal de Ipiranga - PR.

Pôde-se perceber, por meio deste gráfico, que houve um crescimento acentuado, mesmo em diferentes épocas, tanto na rede de abastecimento de água, como na rede coletora de esgoto, na cidade de Ipiranga.

\section{Considerações Finais}

O século passado, marcado por um desenvolvimento tecnológico e econômico sem precedentes na história da humanidade, é também o período da mais intensa degradação da natureza. Os impactos negativos da exploração predatória do meio ambiente têm afetado tanto a qualidade de vida das populações, como também a produção econômica.

É por isso que hoje a questão ambiental permeia o cenário socioeconômico, despertando interesse crescente de governos, empresas e da população. É consenso que o meio ambiente é o mais importante capital que a humanidade detém para o seu próprio desenvolvimento.

No terceiro milênio, por meio da gestão ambiental, afigura-se o desafio de concretizar formas de desenvolvimento sustentável que garantam as condições adequadas para a manutenção e o desenvolvimento da vida humana, como esse exemplo simples e econômico, encontrado no município de Ipiranga, mostrando que não se precisa realizar grandes e dispendiosas obras para trazer aos habitantes do mundo, maior comodidade e ao meio ambiente, maior respeito.

Sabe-se que os maiores problemas encontrados pelos municípios de pequeno porte para a construção de aterros controlados são a indisponibilidade de equipamentos para sua operação, escassez de recursos financeiros e a falta de pessoal técnico qualificado.

Assim, face ao porte do município de Ipiranga, os resultados obtidos com a realização de vários procedimentos, tais como, as sondagens executadas na área indicada para a implantação do projeto, a predominância do solo argiloso, as condições climáticas da região e a inviabilidade econômica em disponibilizar equipamentos de terraplanagem em período integral, optou-se pela implantação de aterro sanitário tipo trincheiras de pequenas dimensões. Esse modelo consiste no preenchimento de valas escavadas com dimensões apropriadas, onde os resíduos são depositados sem compactação e sua cobertura com terra é realizada 
manualmente, reduzindo, assim, seu custo operacional. Os equipamentos de terraplanagem são, portanto, imprescindíveis apenas na fase de abertura das valas.

Vê-se, então, que esta opção foi a mais correta, pois houve uma redução expressiva nos custos para execução do projeto. Além disso, após verificar-se que a vida útil projetada dos aterros é de 26,5 anos, deve-se destacar que poderá, ainda, ser ampliada consideravelmente, caso o município implante sistema de reciclagem de resíduos sólidos urbanos, o qual permitirá reduzir a quantidade de lixo destinada ao terreno.

Pode-se ainda adotar o sistema da passagem dos equipamentos de terraplanagem sobre as valas já fechadas, o que promoverá uma melhor compactação dos resíduos. O município de Ipiranga dispõe de quatro pás-carregadeiras, duas moto-niveladoras e cinco caminhões basculantes, equipamentos estes suficientes para a operação de semi-compactação do lixo.

A preocupação com o meio ambiente ficou evidenciada, mais uma vez, com a implantação do sistema de coleta e recirculação de chorume, preservando o lençol freático de qualquer contaminação.

Vale ressaltar que, houve uma economia considerável na construção das valas, que por acondicionarem pequenas quantidades de resíduos, dispensam a construção de sistemas especiais de drenagem dos gases.

Por fim, pode-se aduzir que no momento em que se ideou a construção dos aterros controlados do tipo trincheiras de pequenas dimensões, foram analisados detalhes múltiplos, os quais beneficiaram tanto a população da cidade como o meio ambiente, visando, também, a economia do município.

\section{Referências Bibliográficas}

BRANCO, Samuel Murgel; ROCHA, Aristides Almeida. Elementos da ciência do ambiente definição de meio ambiente: o lugar do homem na natureza. USP,São Paulo: CETESB/ASCETEBES/BNH, São PauloSB, 1987: 1996.

CASTRO, Ś́lvio (ed.). História da literatura brasileira. 3 vols. 3, Lisboa: Alfa,: 20001999.

DONAIRE, Denis. Gestão ambiental na empresa. 2. ed., São Paulo: Atlas, 1999. 
EHRLICH, Paul R.; EHRLICH, Anne H. População, recursos, ambiente: problemas de ecologia humana. Trad. José Tundisi. São Paulo: , Polígono; , Ed. Da Universidade de São Paulo,: 1994.

INSTITUTO BRASILEIRO DE GEOGRAFIA E ESTATÍSTICA (IBGE). Disponível em: <www.ibge.gov.br>, visitadoAcesso em: 14 /04/abr. 2004.

MOURA, Luiz Antônio. Qualidade e gestão ambiental; . $33^{a}$ ed. São Paulo: Editora Juarez de Oliveira, 2002.

PREFEITURA MUNICIPAL DE IPIRANGA - PR. Projeto de aterro sanitário. 1997.

HUMPHREY, Hubert H. A humanização do meio ambiente. Trad. De Regina Pinto Zingoni. São Paulo, Cultrix:1998.SIMPÓSIO DO INSTITUTO SMITHSONIANO. A humanização do meio ambiente. Trad. Regina Pinto Zingoni. São Paulo: Cultrix, 1968.

TOMMASI, Luis Roberto. A degradação do meio ambiente. 2. ed., São Paulo, : Nobel:, 1997.

Artigo Recebido em 19/07/2004 e aceito para publicação em 13/07/2005. 